\title{
Le Bastion enneigé
}

\section{Mick Rosset}

Etudiant en médecine, $3^{e}$ année, Université de Fribourg

«La boîte aux lettres déborde, il ne sort plus de chez lui et les voisins l'ont aperçu sur son balcon tout dépenaillé.» Je venais de monter à bord de la voiture du médecin après la pause de midi et il me résumait la situation de ce Vaudois de 84 ans exilé au mayens de la Zour depuis la mort de sa femme. "Son fils a essayé de le joindre par téléphone sans succès. Inquiet, il a alors demandé à l'infirmière de passer le voir la semaine passée.»

Nous grimpions toujours plus haut dans le territoire saviésan, tandis que la couche de neige se faisait de plus en plus épaisse. Les derniers chalets dépassés, nous nous arrêtâmes. «Là..., c'est celui avec la voiture bleue devant.» En effet, une petite Toyota dépassait difficilement du mur formé par le chasse-neige, figée désormais dans un glaçon. Le chalet, lui, en contrebas de la route, supportait le poids de l'hiver.

Nous sortîmes de la voiture, prîmes nos affaires et nous dirigeâmes vers l'entrée. Mais un coup d'œil nous mis devant une évidence: le chalet en bois foncé était inaccessible! Il était juste là, à $10 \mathrm{~m}$ mais un épais

\section{Ses maigres joues étaient mal rasées. Les cheveux blancs qui lui restaient se levaient en touffe par endroit. Sa chemise à carreau tachée semblait comme hésitante à être ou ne pas être dans le pantalon, taché et troué lui aussi.}

mur blanc nous mettait au défi de venir à son assaut. Téméraire, je tentai un pas vaillant vers là où j'imaginais le chemin d'accès et m'enfonçai jusqu'à la cuisse dans le froid. Le temps que je me sorte de cette situation, le médecin me tendait une pelle à neige militaire. Une fois la tranchée creusée, nous parvînmes enfin devant la porte en chêne massif et frappâmes... Rien, aucune réponse, nous frappâmes à nouveau... un « $\mathrm{Pu}$ tain!» à l'accent vaudois marqué se fit entendre mais personne ne nous ouvrit. Suite à une troisième tentative, le médecin se décida à pénétrer dans cette forteresse.

Après trois jours de stage, c'était ma deuxième visite à domicile. Un élément de la vie de médecin généraliste que je pensais disparu avec le temps. Une constatation autant agréable que surprenante de savoir que la pratique restait plus ou moins courante. Rencontrer les patients dans leur foyer prend réellement plus de temps, cependant ils sont en général plus détendus qu'au cabinet. Un avantage considérable pour le médecin qui peut appréhender plus facilement la situation et connaître les habitudes de vie du patient.

Frappé en plein nez, j'étais abasourdis par l'environnement tant l'hygiène semblait absente: un mélange de transpiration, de litière pour chat et de nourriture flottait sur un champ de bataille jonché d'habits sales et froissés, de poussière et de tapis aux couleurs oubliées. Un chat sortait d'une fenêtre maintenue ouverte par une litière à moitié renversée qui servait de seul lien avec le monde extérieur. La table autour de laquelle le médecin et son patient discutaient soutenait diverses piles de documents, lettres et classeurs. Un carton de son repas de midi traînait sur une cuisinière au milieu des miettes des précédents repas, une gamelle au sol contenait encore un reste. Il n'y avait plus un seul espace immaculé dans tout ce bunker.

Un survivant hagard nous faisait face au centre de la pièce principale qui constituait la plus grande partie de son antre: «Le médecin qui vient me rendre visite! Eh ben, si je m'attendais à ça! Le médecin qui vient chez moi!» Un air étonné donnait vie à son visage usé par l'âge et la fatigue. Ses petits yeux bleus semblaient sortir d'un long sommeil. Sa bouche restait à demi ouverte, l'air hébété par notre arrivée. Ses maigres joues étaient mal rasées. Les cheveux blancs qui lui restaient se levaient en touffe par endroit. Sa chemise à carreau tachée semblait comme hésitante à être ou ne pas être dans le pantalon, taché et troué lui aussi. Des bretelles au motif d'edelweiss maintenaient ses habits devenus trop larges. Il restait les bras ballants le long du corps, figé. Notre patient était à l'image de son lieu de vie: à l'abandon.

Nous le saluâmes. Il éteignit le documentaire animalier et reposa un verre devenu opaque par la saleté. «Attendez, je vais ranger un peu» dit-il avec empressement et saisit une assiette du sommet d'une pile de lettres non ouvertes. Constatant le manque de place, il la déposa sur un autre tas de documents. Nous étions désormais installés au cœur de son intimité.

Le médecin lui expliqua que sa famille s'inquiétait et qu'on venait voir si tout allait bien. Le patient, lui, ne disait rien. Si ce n'est qu'il allait bien et qu'on avait pas besoin de se déranger. Il paraissait rustre mais ne semblait pas mécontent de nous voir. 
Le généraliste trouva par hasard le dossier de l'infirmière et s'en saisit. «Mais vous n'êtes vraiment pas sorti de chez vous depuis 2 mois? Comment vous faites pour la nourriture?» "J'ai mes réserves de guerre.» répondit-il, laconique. Depuis le début de l'entretien, c'était sa plus longue phrase. Les questions s'enchaînaient mais les réponses tardaient, étaient incomplètes ou absentes. Tous les systèmes furent passés en revue, les poumons, le cœur, les yeux, l'ouie, la mobilité et le moral mais notre patient persistait, tout allait bien. Lorsque le médecin eut fini sa tentative d'anamnèse, nous nous approchâmes pour l'examiner.

«Nous allons écouter votre cœur pour voir si tout va bien!» Un grognement servit de réponse. Je m'approchai avec mon stéthoscope de sa poitrine et me surpris moi-même d'entendre battre un cœur fort et régulier. Probablement étonnant, mais ce fut à ce moment-là, plongé dans les yeux du patient, qu'une réalité me frappa. Et s'il n'avait simplement plus le courage de continuer?
«Est-ce que mon fils a essayé de m’appeler? Mon téléphone fonctionne très bien pourtant...» demanda-t-il d'un ton presque implorant alors que nous étions sur le départ. Toute son apparence prenait brutalement une autre forme: j'imaginais son quotidien, seul, perdu au sommet des mayens d'une région qui n'est pas la sienne, loin de ses proches qui visiblement l'avaient abandonné ou étaient partis. Les jours passent et se ressemblent. Lettres et dossiers médicaux s'accumulent comme la neige, lui survivait seul dans son dernier bastion.

\section{Dossier médical}

Patient de 84 ans, vit seul, veuf depuis 2 ans, bonne santé habituelle, légère HTA, suspicion de malnutrition, état dépressif probable, ne prend pas de médicament, refuse les visites de l'infirmière. Patient réticent à la prise en charge médicale, peu compliant, pas d'antécédent connu... 